\title{
A Review of Two PhD Theses on Emotional Intelligence
}

\author{
N. Gayathri
}

\begin{abstract}
This paper gives a review of two theses - Dr. Mike Gosling's 'The Emotional Intelligence of Managers in Singapore' and Dr. Amber Farooq's 'Effect of Emotional Intelligence on Academic Performance'. It briefly discusses the ideas of the researchers as put forth by them and then gives the reader's observations. The theses have been selected on the basis of emphasizing the fact that emotional intelligence (EI) is important not only in the workplace but also in academics, thus highlighting the significance of EI in every field. This review further helps research scholars working on emotional intelligence, as it guides them on the do's and don'ts in writing a good research paper.
\end{abstract}

Key Words: Emotional Intelligence; Review;

\section{Emotional Intelligence $-\mathbf{a}$ brief introduction}

Emotional intelligence is a concept which has been there from time immemorial, but was ignored or acknowledged as part of human nature (Mayer and Caruso, 2002). In 1990, it was introduced by Peter Salovey and John Mayer as theory which helped in understanding human beings and human relationships in a different perspective - the emotional perspective. They theorized that emotional intelligence was a crucial factor which decided the success of any person in his career or in his personal life. EI became popular after Daniel Goleman's book 'Emotional Intelligence. Why it can matter more than IQ'. "Emotional intelligence, then, refers to the capacity to understand and explain emotions, on the one hand, and of emotions to enhance thought, on the other" (Mayer and Caruso, 2002).

\section{Dr. Mike Gosling's 'The Emotional Intelligence Of Managers In Singapore'}

Mr. Lee Kuan Yew, a minister in Singapore, while fielding questions from a Harvard professor said, "No one can succeed or last long as a leader if he [sic] does not have a high EQ." This remark on Emotional Intelligence (EI became popular after the ground breaking book 'Emotional Intelligence. Why it can matter more than IQ' by Daniel Goleman), prompted Dr. Mike Gosling to research on the emotional competencies of managers in Singapore and analyze whether this made any difference to their success as managers. Michael Gosling's thesis analyses the emotional intelligence of managers in Singapore, explores if there are any differences in the emotional intelligence skills of the western and the local managers in Singapore, and also looks into the possibility of EI having a marked influence on organizational effectiveness.

At the very outset, the author clearly defines the three research questions -

A. are managers in Singapore emotionally intelligent?; is there any difference between the local and the foreign managers?

B. the influence of emotional intelligence on organizational effectiveness and

C. the importance of emotional intelligence in the workplace

The abstract introduces the topic and goes on to specify briefly the purpose, methodology, relevance of the study, and gives a summary of the results and conclusion. The introduction reiterates the research problem and goes on to give the background information - the 1998 Asian financial crisis and the author's own interest and practical knowledge of Emotional Intelligence - which prompted the author to undertake this research. This chapter also discusses the aims, objectives, importance and the limitations of the research undertaken. An outline of the thesis briefs the reader on what to expect in the forthcoming chapters. Though there are slight overlaps as the 'relevance of the study' and the 'value of the study' discuss the same points and the 'summary of the result' and the 'conclusion' again discuss a same idea, the author is successful in defining the research problem and the methodology used.

The literature review traces the evolvement of emotional intelligence from Mayer and Salovey to BarOn and Daniel Goleman, the chief proponents of EI. Through a tabular column, the author gives a neat overview of the chief advocates of EI and their theories. He tells us very briefly but effectively how Bar-On approached EI grouping fifteen components under five composite scale scores - intrapersonal, interpersonal, adaptability, stress management and general mood; Mayer and Salovey's four branch model of EI and Goleman's concept of five emotional competencies namely, self awareness, self regulation, motivation, empathy and social skills. The table also discusses other models of emotional intelligence - Palmer and Stough's SUIET (Swinburne 
Emotional Intelligence Test) now commercially established as Genos EI assessment scale and based on emotional recognition and expression, understanding others' emotions, how emotions direct cognition, emotional management and emotional control. The author then discusses the three different contexts of the study of emotional intelligence - psychometric, theoretical and applied. The author focuses on the literature of the applied context of emotional intelligence as this is the focal point of his thesis. Based on this he classifies the literature in three groups - that which charted the emergence of emotional intelligence, which pointed to the utility of the model MSCEIT (Mayer-Salovey-Caruso Emotional Intelligence Test - the model used by the author in his research) and that which stressed on the influence of emotional intelligence on organizational behavior. Though these three broad areas of literature are discussed under various subheadings, the literature review is too elaborate that at some places the ideas look repetitive. Maybe, the author could have discussed the various advocates of EI and their ideas separately rather than discussing them all under different subheadings. The chapter then moves on to discuss briefly the different models of emotional intelligence that were in vogue for testing the emotional abilities of a person. Of course, the MSCEIT model is analyzed in a detailed manner as this is the model selected by the author for his study. The strengths and also the limitations of this model are thoroughly discussed. The chapter closes with a summary of guidelines for potential research in emotional intelligence and the research questions highlighted again. The research questions are discussed now with the background of the literature reviewed. The author also introduces the reader to the methodology used in dealing with each of the research questions - MSCEIT for the first question and questionnaires for the other two.

The third chapter begins with a brief summary of the contents of the chapter - the methodology used, data collection, data analysis etc. The author then starts with the details on how the participants were chosen. Of the 1,573 prospective research participants, 533 participants were randomly selected from the names of managers listed in local newspapers and a business magazine. The rest 1000 participants were invited from two professional bodies in Singapore - The Chartered Management Institute and the CPA Australia Singapore Division. It was later decided to add data from 40 more managers who attended a training programme conducted by the author himself as the initial response from the short listed participants was very low. The rest of the chapter continues with a detailed explanation of the MSCEIT test that was applied on the participants - the actual number of participants was 139. The procedure in which the data was collected through MSCEIT online testing, questionnaires and executive interviews is discussed in detail. Each and every question of the questionnaire is also discussed and its relevance to the research is established. The chapter then moves on to discuss 'EASEQuadrant' - a model created by the author for interpreting an individual's emotional intelligence scores and also for developing emotional intelligence in an individual. The four quadrants - 'evaluate my perceptions', 'affirm changed behavior', strengthen emotional intelligence' and 'emphasize choice and detachment' - are explained and the way it has been used in this study is also discussed in detail.

The concluding chapter analyses the results of the test and provides with answers for all the research questions. It concludes that the Singaporean managers have an average level of emotional intelligence and that there is no considerable difference in the emotional intelligence abilities of the local and the foreign managers and the affirmation of the managers that emotional intelligence was important for organizational and managerial effectiveness. Other inferences from the data - a typical Singapore manager who had an average emotional insight was likely to be a male of around 40 years of age; male managers in Singapore were comparatively better emotionally intelligent than the female managers - are also discussed.

\section{Observations}

Though the thesis is based on thorough research, the organization of thoughts and ideas seems to leave much room for questioning. Also, some views are repeated time and again in all the chapters. For example, when the 'Preliminaries' has a glossary and a list of abbreviations, the 'Introduction' again has a definition of terms. The definition of terms could have been incorporated in the glossary. The literature review goes on to almost a hundred pages and the reader wonders if one third of the thesis should be devoted to literature review alone. Also, the review is done based on topics - traditional view of emotions; intelligence; and emotional intelligence. Though this cannot be taken as a wrong approach, the reader feels that if the literature review had been done based on the different proponents of emotional intelligence, focusing on Mayer and Salovey's stance; Caruso's standpoint; Goleman's observations, and related them to the research problem, then there would have been better clarity in communicating what the author wanted to prove. Not only that, after the author discusses the different subtopics, he moves on to a discussion of the various tests or models that enable assessing the emotional intelligence of a person, summarizes, speaks on the MSCEIT- the model used by the author - and again branches off to other subtopics on emotional intelligence, organizational effectiveness and individual success. It would have been better if the author had discussed all the subtopics and then moved on to the discussion on the models of EI. 


\section{Dr. Amber Farooq's 'Effect of Emotional Intelligence on Academic Performance'}

Dr. Farooq's thesis begins with a list of tables and graphs. The abstract is crisp and introduces the reader to the research problem, the methods used and the result. The introduction, at the very outset, firmly grounds the importance of emotional intelligence for a person's well being in all walks of life. It then goes on to discuss the nature of emotions and speaks on the classifications of the basic emotions as done by various psychologists -

a) Descartes' list of six primitive emotions: wonder, hatred, love, desire, joy and sadness; b) Shand's list of fear, anger, disgust, curiosity, joy, sorrow-repugnance-aversion, self-display and self-abasement.

The author argues with enough evidence and conviction that emotions are the basis of any person's character. She discusses the stalwarts in this field - Shand, Izard, Mc Crae, Arenberg and others - who had believed and proved the association between emotions and character traits, stability in outlook, etc. The connection between emotions and inter-personal skills is also established. The factors that influence a person's emotional well being - stressful situations, an expectant mother's stress level and nutritional habits - are all discussed. With these arguments as the basis, the author then moves on to analyze a child's emotional personality and its effect on the child's social inter personal skills later in life. The factors, according to the author, that define a child's character and its emotional life are: inherited temperamental qualities, personalities of the parents, quality of the schools attended, the child's relationship with its social group, the child's ordinal position in the family and last but not the least the societal set up or background when the child is in its early adolescence. The author also argues that the role of the parents is colossal when it comes to shaping the child's capacity to manage and regulate emotions. As children move into the adolescent stage, they find it more challenging to cope up with the rapid changes and development in their physique and psyche. Their relationship with their parents also enters a turbulent phase as they are confronted with mood swings, anger, helplessness and an urge to question authority - any type of authority, be it parents at home or teachers at school. Here again the author reiterates and insists on the enormous responsibility that the parents have to shoulder for the emotional well being of their children. In fact, the author concludes with evidence that the parents' role is pivotal in deciding the child's social behavior.

Having thus established the factors that mould a child's social and emotional life, the author then moves on to discuss the effect of a child's personality on its academic performance. At the very beginning, it is ascertained that the EQ level of a student plays a bigger role than the IQ of the student in his academic achievements. Apart from this, the personality traits of the teacher - the teacher's expectations from the student; interaction; and the teacher's way of maintaining discipline - also play a significant role in a student's academic accomplishments. In this context, the relevance of the right atmosphere at school, the quality of teachers, and the curriculum and the aims of the school to the emotional stability of the students is discussed. With all the above arguments as a background, the author now delves into the traditional definition of emotional intelligence, discusses on EQ vs. IQ, establishes emotional intelligence as an important component of personality, and argues how emotional intelligence helps in the management of temperaments. The thesis then moves on to tackle the actual research problem - the role of EI in schools and colleges - with a brief literature review. The chapter then ends with a discussion on various topics - role of EI in the workplace, EI and interpersonal relationships, EI and stress management, etc.

After a brief observation on the literature review, the hypotheses is discussed followed by the methodology - questionnaire based on EQ-I designed by Reuven Bar- On. The next chapter discusses the results of the study in the form of tables and graphs. The author concludes that a student's emotional intelligence, inter personal skills, intra personal skills and stress management abilities has a considerable effect in his/her's academic performance. All the seven hypotheses are then discussed and analyzed based on the tables and graphs. The thesis concludes with suggestions for future research and the implications of the current study.

\section{Observations}

A thorough research by the author establishes beyond doubt the relevance and importance of emotional intelligence in academic performance. Nevertheless, the reader feels more care could have gone into the chapterisation. The chapter titled 'Introduction' does not stop with that, but goes on to literature review as well. Rather, if the author had given the hypotheses (considering the fact that there are seven) after a brief introduction and then gone for literature review under a separate chapter, there would have been better clarity for the reader to comprehend.

\section{Conclusion}

After a thorough reading of the two theses, the reader concludes that however well a research is undertaken, presentation plays an equally important role and if this aspect is ignored, the respect for the research goes down a few notches. 


\section{Works Cited}

[1] Amber, Farooq. Effect of Emotional Intelligence on Academic Performance. Diss. Web. 28 Feb. 2011. <http://prr.hec.gov.pk/Thesis/889.pdf

[2] Gosling, Michael. Measuring emotional intelligence of managers in Singapore and the

[3] application of emotional intelligence for individual and organisation effectiveness.

[4] An exploratory study. Diss. Web. 28 Feb. 2011.<http://www.goslings.net/pdf/Dr_Mike_Gosling_Doctoral_Thesis_2006.pdf

[5] Mayer, J.D., \& Caruso, D. (2002). The effective leader: Understanding and applying

[6] emotional intelligence. Ivey Management Services.

[7] MLA Handbook for Writers of Research Papers. Affiliated East-West Press Pvt. Ltd. 2009. Print. 